\title{
A Microstructural Investigation of Model Solid State Hydrodesulfurization Catalysts
}

\author{
AMIT SACHDEV, JAMES LINDNER, JOHANNES SCHWANK, \\ AND MARIA A. VILLA GARCIA* \\ Department of Chemical Engineering, University of Michigan, Ann Arbor, \\ Michigan 48109-2136; and *Departamento de Química Organometálica, \\ Facultad de Química, Universidad de Oviedo, Oviedo-33071, Spain
}

Received August 11, 1989; in revised form April 3, 1990

\begin{abstract}
Model molybdenum disulfide-based solid state synthesis catalysts have been prepared and tested catalytically in the HDS of thiophene. Both promoted and sulfur-deficient samples were prepared and the kinetic analyses were done at temperatures ranging from $473-673 \mathrm{~K}$ and atmospheric pressure. Structural characterization was carried out using X-ray diffraction and analytical and high resolution electron microscopy. The results indicate that the active catalysts possess a high degree of disorder in the $(10 \overline{10}),(10 \overline{1}),(10 \overline{1} 2)$ directions, which represent the edges of the $\mathrm{MoS}_{2}$ crystal. This work also establishes that both Group VIII promotion and sulfur deficiency lead to similar structural changes in the molybdenum sulfide lattice of this specific solid state system. These structural traits can be correlated with increased HDS activity. (c) 1990 Academic Press, Inc.
\end{abstract}

\section{Introduction}

The process of hydrodesulfurization (HDS) involves the removal of sulfur from crude oil feedstocks and is a very important concern of the oil industry for two reasons. From a catalytic viewpoint, sulfur acts as a poison for Pt-based reforming catalysts which are used to form gasoline from the desulfurized crude. From an ecological standpoint, removing the sulfur protects the environment by decreasing $\mathrm{SO}_{x}$ pollution. Due to the dependence of industrialized economies on fossil fuels and the scale on which HDS catalysts are employed (an estimated 44,200 tons per year in 1986) (1), studies focusing on the nature of the catalytically active species have been both numerous and extensive.

0022-4596/90\$3.00

Copyright 1990 by Academic Press, lac.

All rights of reproduction in any form reserved.
HDS catalysts typically consist of a Group VI metal oxide, such as $\mathrm{MoO}_{3}$ or $\mathrm{WO}_{3}$, promoted by a Group VIII oxide, such as $\mathrm{CoO}$ or $\mathrm{NiO}$, supported on alumina. Currently, the workhorse of the HDS industry is the $\mathrm{CoO} / \mathrm{MoO}_{3}$ alumina-supported catalyst, which must be sulfided in order to obtain the active species, whose structure is still under debate. Much of the research conducted in the last 20 years has focused on the nature of the active sites for HDS. This effort has concentrated on seeking a connection between the $\mathrm{MoS}_{2}$ phase-promoter interaction and the observed catalytic activity. The literature provides many different models to explain the promotional effect $(2-12,24)$. A widely accepted model of the active HDS site assumes that HDS activity is related to the presence of covalently bonded $\mathrm{Co}$ on 378 
$\mathrm{MoS}_{2}$ edge planes. This and related models have also come to be known in the HDS literature as the "edge decoration" or "CoMoS" models $(2,24)$. Recent studies have provided strong support for this "CoMoS" phase as being responsible for catalytic activity $(13,14)$. There is no undisputed method for accurately quantifying the number of active HDS sites on a given catalyst which would be needed for normalizing and comparing catalytic activities of different catalysts. Attempts have been made to normalize the catalytic activity for hydrodesulfurization in terms of molecules converted per unit edge area of the $\mathrm{MoS}_{2}$, which in turn was measured by adsorbing gases such as $\mathrm{O}_{2}, \mathrm{NO}$, or $\mathrm{CO}$. These normalization methods have recently been reviewed by Prins $e t$ al. (2). A major problem with the use of terms such as "edge areas" and "edge decorated" is that from a crystallographic viewpoint the notion of such a CoMoS phase on $\mathrm{MoS}_{2}$ edge planes is structurally ill defined. In this context, it is important to distinguish between the various crystallographic edge planes, and particle "edges" representing the termination of a crystallite, respectively. Given the layered structure of $\mathrm{MoS}_{2}$ and its high degree of anisotropy, it is very difficult to quantitatively relate structural parameters such as "edge area" to catalytic activity.

This paper presents our results on a series of unsupported HDS catalysts prepared via solid state reactions and the relationship between their structure and activity. The preparation procedure is similar to that developed by Farragher and Cossee (7) in their study of hydrogenation reactions over $\mathrm{MoS}_{2}$ and $\mathrm{WS}_{2}$. Until now the standard methods used to synthesize HDS catalysts $(8,15,16)$ have led to a formation of mixed phases that require thermal and sulfiding pretreatments prior to use, and the resulting materials are very difficult to characterize, especially in the case of catalysts supported on polycrystalline substrates such as $\mathrm{Al}_{2} \mathrm{O}_{3}$. Unsup- ported model catalysts such as the solid state HDS catalysts described here offer the opportunity to examine structural details with high resolution electron microscopy, unobscured by interference of support materials. We feel that the solid state route presented in this work allows us to more accurately describe the microstructure of our catalysts and link this to the observed HDS activity.

\section{Experimental}

\section{Synthesis}

Two series of hydrodesulfurization solid state catalysts were prepared by combining the elemental powders of molybdenum, sulfur, and a promoter component. These samples had the general stoichiometry of $P_{2 x} \mathrm{Mo}_{1-x} \mathrm{~S}_{2}$, with $x$ lying between 0.025 and 0.3 , and where $P$ represents the promoter element of cobalt or iron. The powders were mixed thoroughly, placed in a quartz tube, and evacuated to about $0.1 \mathrm{~Pa}$. The sealed tube was heated for $24 \mathrm{hr}$ at $783 \mathrm{~K}$ to enable the solid state reaction to take place. A more detailed description of the catalyst preparation has been published elsewhere $(17,18)$. Along with the promoted samples, stoichiometric $\mathrm{MoS}_{2}$ and sulfur-deficient nonstoichiometric $\operatorname{MoS}_{1.95}$ were also prepared using similar synthesis procedures. Table I lists the various solid state catalysts along with their BET surface areas. The promoted catalysts will hereafter be referred to by their promoter prefix labels. An industrially supplied (Katalco) HDS catalyst consisting of $\mathrm{CoO}$ and $\mathrm{MoO}_{3}$ supported on high surface area alumina was also examined in order to compare its microstructural characteristics with those of the solid state samples.

\section{Catalytic Activity Measurements}

The hydrodesulfurization of thiophene was chosen as a suitable test reaction to measure the catalytic activity of these sam- 
TABLE I

Bet Surface Areas and Phases Detected by X-Ray Diffraction

\begin{tabular}{|c|c|c|c|c|}
\hline Catalyst & $\begin{array}{c}\mathrm{P} / \mathrm{Mo}^{a} \\
\text { (Atomic ratio) }\end{array}$ & $\begin{array}{l}\text { BET surface area } \\
\left(\mathrm{m}^{2} / \mathrm{g}\right)\end{array}$ & Fresh catalyst & Used catalyst \\
\hline $\begin{array}{l}\operatorname{MoS}_{2} \\
\operatorname{MoS}_{1.95}\end{array}$ & $\begin{array}{l}0.0 \\
0.0\end{array}$ & $\begin{array}{l}1 \\
20\end{array}$ & $\begin{array}{l}\mathrm{MoS}_{2} \\
A^{b}+\mathbf{M o}\end{array}$ & $\begin{array}{l}\mathrm{MoS}_{2} \\
A+\mathbf{M o}\end{array}$ \\
\hline \multicolumn{5}{|c|}{ Cobalt series } \\
\hline $\mathrm{Co}_{0.05} \mathrm{Mo}_{0.975} \mathrm{~S}_{2}$ & 0.051 & 26 & $A+\mathrm{Mo}+\mathrm{CoS}_{2}$ & $\mathrm{Mo}+A+\mathrm{CoO}(\mathrm{OH})$ \\
\hline $\mathrm{Co}_{0.1} \mathbf{M o}_{\mathbf{0 . 9 5}} \mathrm{S}_{2}$ & 0.105 & 14 & $A+\mathrm{Mo}_{\mathrm{O}}+\mathrm{CoS}_{2}$ & $\mathrm{Mo}+A+\operatorname{CoO}(\mathrm{OH})$ \\
\hline $\mathrm{Co}_{0.2} \mathrm{Mo}_{0,9} \mathrm{~S}_{2}$ & 0.222 & 14 & $A+\mathrm{Mo}+\mathrm{CoS}_{2}$ & $\mathrm{Mo}+A+\mathrm{Co}_{9} \mathrm{~S}_{8}+\mathrm{CoO}(\mathbf{O H})$ \\
\hline $\mathrm{Co}_{0.3} \mathrm{Mo}_{0.85} \mathrm{~S}_{2}$ & 0.353 & 15 & $A+\mathrm{Mo}+\mathrm{CoS}_{2}$ & $\mathrm{Mo}+A+\mathrm{Co}_{9} \mathrm{~S}_{8}+\mathrm{CoO}(\mathrm{OH})$ \\
\hline $\mathrm{Co}_{0.5} \mathrm{Mo}_{0.75} \mathrm{~S}_{2}$ & 0.667 & 1 & $\begin{aligned} \mathrm{MoS}_{2} & +\mathrm{CoS}_{2}+\mathrm{Co}_{3} \mathrm{~S}_{4}+ \\
\mathrm{Cu}_{4} \mathrm{~S}_{3} & +\mathrm{CoMo}_{2} \mathrm{~S}_{4}+\mathrm{Mo}\end{aligned}$ & $\begin{array}{l}\mathrm{MoS}_{2}+\mathrm{Co}_{9} \mathrm{~S}_{8}+\mathrm{Co}_{3} \mathrm{~S}_{4}+ \\
\mathrm{CoMo}_{2} \mathrm{~S}_{4}+\mathrm{Mo}\end{array}$ \\
\hline $\mathrm{Co}_{0.6} \mathrm{Mo}_{0.7} \mathrm{~S}_{2}$ & 0.857 & 1 & $\begin{array}{l}\mathrm{MoS}_{2}+\mathrm{Co}_{3} \mathrm{~S}_{4}+ \\
\mathrm{Co}_{4} \mathrm{~S}_{3}+\mathrm{CoMo}_{2} \mathrm{~S}_{4}+\mathrm{Mo}\end{array}$ & $\begin{array}{l}\mathrm{MoS}_{2}+\mathrm{Co}_{9} \mathrm{~S}_{8}+\mathrm{Co}_{3} \mathrm{~S}_{4}+ \\
\mathrm{CoMo}_{2} \mathrm{~S}_{4}+\mathrm{Mo}^{-}\end{array}$ \\
\hline \multicolumn{5}{|c|}{ Iron series } \\
\hline $\mathrm{Fe}_{0.05} \mathrm{Mo}_{0.975} \mathrm{~S}_{2}$ & 0.051 & 15 & $A+\mathbf{M o}+\mathbf{F e S}_{2}$ & $\mathbf{M o}+A+\mathrm{Fe}_{1-\mathbf{x}} \mathbf{S}$ \\
\hline $\mathrm{Fe}_{0.1} \mathrm{Mo}_{0.95} \mathrm{~S}_{2}$ & 0.105 & 21 & $A+\mathbf{M o}+\mathbf{F e S}_{2}$ & $\mathbf{M o}+A+\mathrm{Fe}_{1-\mathbf{x}} \mathbf{S}$ \\
\hline $\mathrm{Fe}_{0.2} \mathrm{Mo}_{0.9} \mathrm{~S}_{2}$ & 0.222 & 16 & $A+\mathrm{Mo}+\mathrm{FeS}_{2}$ & $\mathrm{Mo}+A+\mathrm{Fe}_{\mathbf{1}} \mathbf{S}$ \\
\hline $\mathrm{Fe}_{0.4} \mathrm{Mo}_{0.8} \mathrm{~S}_{2}$ & 0.353 & 20 & $A+\mathrm{Mo}+\mathrm{FeS}_{2}$ & $\mathbf{M o}+A+\mathbf{F e}_{1-\mathrm{x}} \mathbf{S}$ \\
\hline $\mathrm{Fe}_{0.5} \mathrm{Mo}_{0.75} \mathrm{~S}_{2}$ & 0.667 & 6 & $A+\mathrm{Mo}+\mathrm{FeS}_{2}$ & $\mathrm{Mo}+A+\mathrm{Fe}_{1-\mathbf{x}} \mathrm{S}$ \\
\hline $\mathrm{Fe}_{0.6} \mathrm{Mo}_{0.7} \mathrm{~S}_{2}$ & 0.857 & 6 & $A+\mathrm{Mo}+\mathrm{FeS}_{2}$ & $\mathrm{Mo}+A+\mathrm{Fe}_{1-\mathrm{x}} \mathrm{S}$ \\
\hline
\end{tabular}

Note. The phases in boldface are present in only minor proportions or as traces.

a Promoter/molybdenum atomic ratio.

${ }^{b} A$ is a nonstoichiometric molybdenum disulfide-based phase.

ples. The catalysts were pretreated in a helium flow for $30 \mathrm{~min}$ at $673 \mathrm{~K}$. The reactant mixture, consisting of a $\mathrm{H}_{2}$ /thiophene flow, was passed over the catalyst bed maintained within a temperature range of $473-673 \mathrm{~K}$. The reaction rates were expressed as a turnover of molecules of thiophene per total molybdenum atoms in the sample per second. It is a common practice in HDS catalysis to normalize the reaction activity in terms of $\mathrm{MoS}_{2}$ "edge" areas. But this method can be somewhat misleading as there is no unambiguous technique to determine these "edge" areas.

\section{Structural Characterization}

The advantage of using bulk unsupported sulfides is that they can be readily analyzed for their phase composition by X-ray diffraction. The degree of crystallinity can also be inferred from the linewidths of the Xray peaks. While $\mathrm{X}$-ray diffraction provided information of a more average nature re- garding the crystalline phases present, electron microscopy was utilized to learn more about the microstructural makeup of the samples. The elemental analysis by EDX and microdiffraction studies were performed on a JEOL $2000 \mathrm{FX}$ analytical electron microscope. Additional AEM investigations were performed on a dedicated STEM (VG HB501) equipped with a field emission gun capable of forming very small electron probes. High resolution electron microscopy on a JEOL $4000 \mathrm{EX}$ was used to examine the structure and morphology of the catalysts at an atomic scale. Due to an initial concern of damaging the specimen by electron beam irradiation, the HREM work was done primarily at an accelerating voltage of $200 \mathrm{kV}$. However, at a later stage of the investigation, as no significant irradiation effects were observed at $400 \mathrm{kV}$, the remaining specimens were examined at this higher voltage. The specimen preparation for electron microscopy consisted simply of 


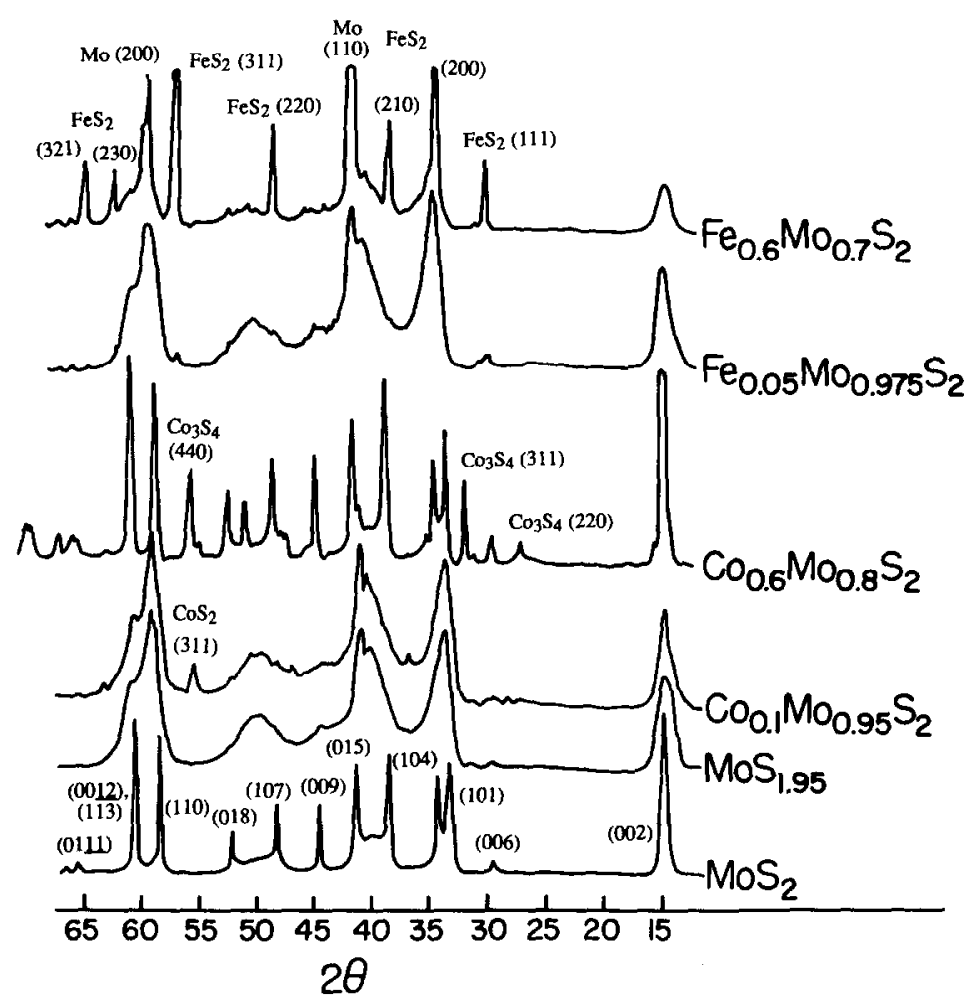

FIG. 1. Representative X-ray diffraction profiles from the cobalt and iron promoted series of freshly synthesized samples. Plots from $\mathrm{Co}_{0.1}, \mathrm{Co}_{0.6}, \mathrm{Fe}_{0.05}$, and $\mathrm{Fe}_{0.6}$ are shown. Stoichiometric $\mathrm{MoS}_{2}$ and nonstoichiometric $\mathrm{MoS}_{1.95}$ are also included for comparison.

depositing a few drops of the isopropanolsuspended catalyst powder on a holey carbon-covered copper grid.

\section{Results and Discussion}

\section{X-Ray Diffraction}

The powder X-ray diffraction patterns indicated the presence of a mixture of crystalline phases in both the Co-series and the $\mathrm{Fe}$-series solid state catalysts (Fig. 1). In addition, the crystalline phases in stoichiometric $\mathrm{MoS}_{2}$ and nonstoichiometric $\mathrm{MoS}_{1.95}$ were also examined (Table I). The details of the phase determination by $\mathrm{X}$-ray diffraction have been described in previous publications $(17,18)$. Briefly, for the samples containing low cobalt loadings $\mathrm{Co}_{0.05}-\mathrm{Co}_{0.3}$, the majority of the peak intensity could be attributed to the presence of a nonstoichiometric molybdenum sulfide phase. This was confirmed by comparing the $\mathrm{X}$-ray peak positions and shapes with that of the nonstoichiometric $\mathrm{MoS}_{1.95}$ sample. Generally, the peaks were considerably broadened and weaker in intensity relative to that of the stoichiometric $\mathrm{MoS}_{2}$. These phenomena are typical of nonstoichiometric materials where, in this instance, the creation of anionic sulfur vacancies in $\mathrm{MoS}_{2}$ resulted in $\mathrm{X}$-ray line broadening. This cannot be solely assigned to crystallite size or surface area effects but is most likely caused by the presence of defects in the solid state samples (19). This aspect will be examined in greater detail in the electron microscopy investiga- 
tions. In addition to the nonstoichiometric phase, small amounts of metallic molybdenum and cobalt sulfide with a cubic pyrite structure werc also detected. With increasing amounts of cobalt, such as in samples $\mathrm{Co}_{0.5}$ and $\mathrm{Co}_{0.6}$, the cobalt sulfide peak intensity increased. Moreover, in these latter two specimens, the peaks attributed to the nonstoichiometric molybdenum sulfide could no longer be detected as attested to by the narrowing of the $\mathrm{MoS}_{2}$ line widths. The samples with high cobalt loadings, namely $\mathrm{Co}_{0.5}$ and $\mathrm{Co}_{0.6}$, also showed traces of Mo and various other cobalt sulfides including $\mathrm{Co}_{3} \mathrm{~S}_{4}, \mathrm{Co}_{4} \mathrm{~S}_{3}$, and $\mathrm{CoMo}_{2} \mathrm{~S}_{4}$.

The Fe-series solid state state samples had X-ray diffraction profiles very similar to the Co-series. The non stoichiometric molybdenum sulfide phase was present in all samples irrespective of the iron loading. With rising iron loadings, the amounts of
$\mathrm{FeS}_{2}$ of the pyrite type increased. It should be noted that no evidence of any oxide phases was observed in either the cobaltor iron-promoted materials.

\section{Catalytic Activity}

In order to justify these solid state samples as useful for hydrodesulfurization, they had to be tested for their catalytic activity. The activity and product selectivity results are presented in Table II. The data shown here were taken after $2 \mathrm{hr}$ on stream, atmospheric pressure, and a temperature of 573 K. The feed stream consisted of 2.7 vol\% thiophene, the balance being hydrogen.

For the $\mathrm{Co}_{2 x} \mathrm{Mo}_{1-x} \mathrm{~S}_{2}$ series, the samples with cobalt loadings from $\mathrm{Co}_{0.05}$ to $\mathrm{Co}_{0.3}$ had significantly higher activities, up to an order of magnitude greater, than the two catalysts with the high cobalt loadings. Also, it was observed that the stoichiometric $\mathrm{MoS}_{2}$ was far

TABLE II

HDS ACTIVITY AND SELECTIVITY AT 573K

\begin{tabular}{|c|c|c|c|c|c|c|c|c|c|c|c|}
\hline \multirow[b]{2}{*}{ Catalyst } & \multirow[b]{2}{*}{ TOF $\left(\sec ^{-1}\right)$} & \multicolumn{10}{|c|}{$\%$ Selectivity } \\
\hline & & $\mathrm{C}_{2}$ & $C_{2}=$ & $\mathrm{C}_{3}$ & $\mathrm{C}_{3}=$ & $i C_{4}$ & $n \mathrm{C}_{4}$ & $1 C_{4}=$ & $\begin{array}{c}i \mathrm{C}_{4=} \& \\
1,3 \mathrm{C}_{4}\end{array}$ & $c \mathrm{C}_{4}$ & $t \mathrm{C}_{4}$ \\
\hline $\mathrm{MoS}_{2}$ & $3.16^{*} 10^{-7}$ & 0.0 & 12.8 & 6.7 & 38.2 & 0.0 & 0.0 & 15.7 & 8.3 & 12.6 & 5.8 \\
\hline $\operatorname{MoS}_{1.95}$ & $2.22 * 10^{-5}$ & 0.5 & 0.0 & 1.9 & 1.9 & 0.0 & 76.8 & 3.6 & 0.0 & 10.0 & 5.1 \\
\hline \multicolumn{12}{|c|}{ Cobalt series } \\
\hline $\mathrm{Co}_{0.05} \mathrm{Mo}_{0.975} \mathrm{~S}_{2}$ & $4.84 * 10^{-5}$ & 0.4 & 0.0 & 0.6 & 0.0 & 0.0 & 71.4 & 5.8 & 0.0 & 14.1 & 7.5 \\
\hline $\mathrm{Co}_{0.1} \mathbf{M o}_{0.95} \mathrm{~S}_{2}$ & $1.22 * 10^{-5}$ & 0.7 & 0.3 & 1.0 & 0.0 & 0.0 & 56.2 & 8.4 & 0.0 & 21.7 & 11.5 \\
\hline $\mathrm{Co}_{0.2} \mathrm{Mo}_{0.9} \mathrm{~S}_{2}$ & $6.65^{*} 10^{-5}$ & 0.3 & 0.0 & 0.4 & 0.0 & 0.0 & 64.3 & 7.8 & 0.0 & 17.6 & 9.4 \\
\hline $\mathrm{Co}_{0.3} \mathrm{Mo}_{0.85} \mathrm{~S}_{2}$ & $9.12 * 10^{-5}$ & 0.1 & 0.0 & 0.3 & 0.0 & 0.0 & 79.3 & 4.3 & 0.0 & 10.5 & 5.5 \\
\hline $\mathrm{Co}_{0.5} \mathrm{Mo}_{0.75} \mathrm{~S}_{2}$ & $0.54 * 10^{-5}$ & 0.0 & 1.5 & 0.0 & 0.0 & 0.0 & 6.4 & 21.6 & 0.0 & 47.7 & 22.8 \\
\hline $\mathrm{Co}_{0.6} \mathrm{Mo}_{0.7} \mathrm{~S}_{2}$ & $0.18 * 10^{-5}$ & 0.0 & 0.0 & 0.0 & 0.0 & 0.0 & 7.5 & 44.7 & 0.0 & 29.2 & 18.7 \\
\hline \multicolumn{12}{|c|}{ Iron series } \\
\hline $\mathrm{Fe}_{0.05} \mathrm{Mo}_{0.975} \mathrm{~S}_{2}$ & $3.40 * 10^{-5}$ & 0.0 & 0.9 & 0.5 & 0.0 & 0.0 & 58.6 & 8.3 & 0.0 & 20.4 & 11.1 \\
\hline $\mathrm{Fe}_{0.1} \mathrm{Mo}_{0.95} \mathrm{~S}_{2}$ & $8,11^{*} 10^{-5}$ & 0.1 & 0.0 & 0.3 & 0.0 & 0.0 & 78.2 & 4.6 & 0.0 & 10.9 & 5.9 \\
\hline $\mathrm{Fe}_{0.2} \mathrm{Mo}_{0.9} \mathrm{~S}_{2}$ & $8.61 * 10^{-5}$ & 0.3 & 0.0 & 0.3 & 0.0 & 0.0 & 77.1 & 4.6 & 0.0 & 11.6 & 6.1 \\
\hline $\mathrm{Fe}_{0,4} \mathrm{Mo}_{0,8} \mathrm{~S}_{2}$ & $9.78 * 10^{-5}$ & 0.0 & 0.1 & 0.3 & 0.0 & 0.0 & 67.4 & 7.1 & 0.0 & 16.4 & 8.7 \\
\hline $\mathrm{Fe}_{0.5} \mathrm{Mo}_{0.75} \mathrm{~S}_{2}$ & $1.65^{*} 10^{-5}$ & 0.2 & 0.0 & 0.3 & 0.0 & 0.0 & 79.0 & 4.5 & 0.0 & 10.3 & 5.5 \\
\hline $\mathrm{Fe}_{0.6} \mathrm{Mo}_{0.7} \mathrm{~S}_{2}$ & $7.60^{*} 10^{-5}$ & 0.2 & 0.2 & 0.2 & 0.0 & 0.0 & 37.9 & 14.2 & 0.0 & 30.5 & 16.8 \\
\hline
\end{tabular}

Note. All data taken after $2 \mathrm{hr}$ on stream, atmospheric pressure, and $573 \mathrm{~K}$. 


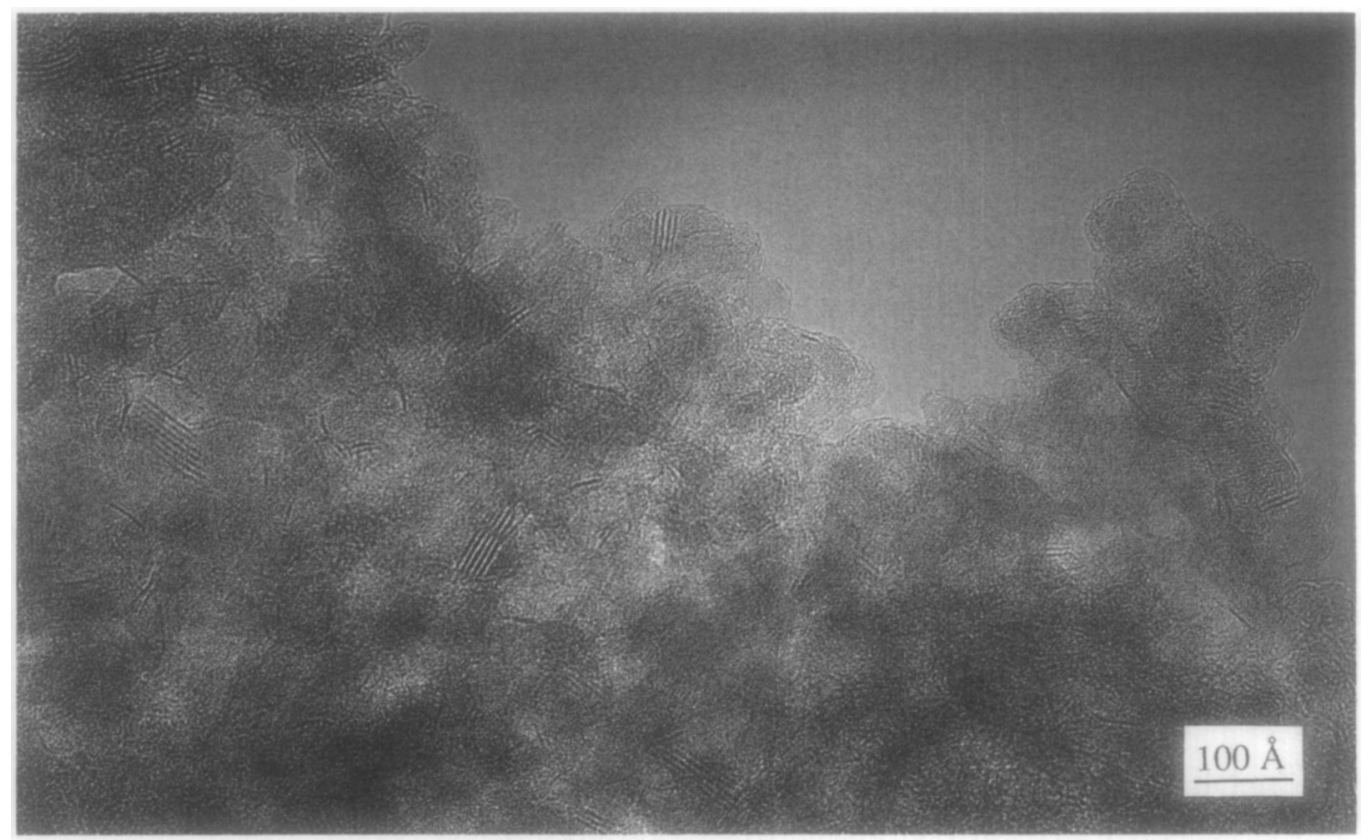

FIG. 2. A high resolution electron micrograph of a sulfided industrial (Katalco) HDS catalyst which consisted of $\mathrm{CoO}-\mathrm{MoO}_{3}$ supported on alumina. Note the slabs of $\mathrm{MoS}_{2}$ dispersed on the $\mathrm{Al}_{2} \mathrm{O}_{3}$ indicated by the short dark $6.15 \AA$ lattice fringes.

less active than the nonstoichiometric $\mathrm{MoS}_{1.95}$. From the large disparity between the high and low activity groups of catalysts, it can be expected that there must be some sort of structural and/or compositional difference between the samples with high and low catalytic activity. This was confirmed when it was determined that all the high activity catalysts contained the nonstoichiometric molybdenum sulfide phase, whereas such a phase was not detected in the catalysts with high cobalt content having low activity.

Higher catalytic activities were observed for all the iron-promoted materials relative to stoichiometric $\mathrm{MoS}_{2}$ as well. It was determined from the $\mathrm{X}$-ray diffraction profiles that all the iron-promoted catalysts synthesized contained the nonstoichiometric molybdenum sulfide phase. From these results, it would appear as though the high reactivity coincided with the presence of this nonstoichiometric phase in both the $\mathrm{Fe}$ and Co series.

\section{Electron Microscopy}

3.1. Alumina-supported HDS catalysts. A typical industrially supplied (Katalco) hydrodesulfurization catalyst contains $\mathrm{CoO}$ and $\mathrm{MoO}_{3}$ supported on a high surface area alumina support. This catalyst is presulfided in a $\mathrm{H}_{2} \mathrm{~S} / \mathrm{H}_{2}$ stream at high temperatures before being utilized. The sulfidation of the oxide precursors leads to the formation of a molybdenum sulfide phase. The role and location of the cobalt promoter is still not completely understood, although it has been suggested that a "Co-Mo-S" phase, composed of cobalt atoms residing on the $\mathrm{MoS}_{2}$ edge planes, is formed $(11,12,20)$. A high resolution electron micrograph (Fig. 2) of a sulfided Katalco catalyst illustrates the presence of dispersed $\mathrm{MoS}_{2}$ on the alumina as 


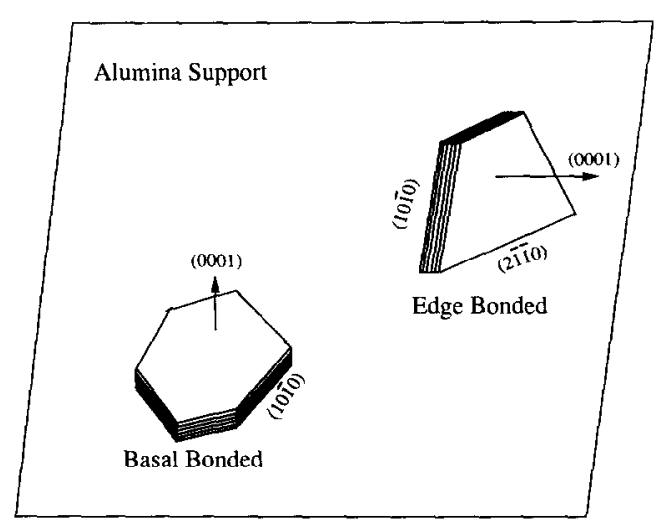

FIG. 3. Schematic of the edge and basal plane bonding configurations of the $\mathrm{MoS}_{2}$ slabs on the alumina support. (Adapted from Refs. ( $I$ and 22).)

indicated by the short black lines. These features represent the (0002) or basal planes of $\mathrm{MoS}_{2}$ with spacings of $6.15 \AA$. Multislice computations have shown that each of the black lines signifies a $\mathrm{S}-\mathrm{Mo}-\mathrm{S}$ sheet $(2 I)$. These slabs or stacks of $\mathrm{MoS}_{2}$, as they have come to be known in the catalyst literature, have been studied extensively by TEM techniques on alumina-supported powder samples as well as on model substrates (22). It has been reported that, depending upon the temperature of sulfidation, these $\mathrm{MoS}_{2}$ stacks can either be edge bonded or basal bonded to the alumina planes. At a sulfidation temperature of $670 \mathrm{~K}$, microdiffraction studies have shown that the $\mathrm{MoS}_{2}$ is edge bonded with its $\{2 \overline{1} 10\}$ plane in contact with the alumina, while the $\{10 \overline{1} 0\}$ set of edge planes are exposed to the gas phase reactants (23). But when the sulfidation temperature was increased to $870 \mathrm{~K}$, the $\mathrm{MoS}_{2}$ layers were found to be bonded to the substrate with the basal plane (Fig. 3). It is generally accepted that the edge planes of the $\mathrm{MoS}_{2}$ crystal are mainly responsible for the beneficial activity trends observed in these catalysts due to the coordinative unsaturation of the sulfur atoms located on these planes (24). As can be observed in the HREM mi- crograph (Fig. 2), the polycrystalline nature of the alumina support makes it virtually impossible to study the catalytically interesting edge planes, and only the (0002) basal planes are easily visible. This interference in the imaging of edge planes by the alumina substrate can be avoided in the unsupported, solid state-synthesized $\mathrm{Co}$ - and $\mathrm{Fe}$ containing molybdenum sulfide catalysts. These model materials, therefore, permit the examination of their structure in greater detail.

3.2 Stoichiometric $\mathrm{MoS}_{2}$. Molybdenum disulfide is characterized by a layered structure and has a hexagonal unit cell (25). The Mo atoms are coordinated with six sulfur atoms in a trigonal prismatic configuration. Although a less common rhombohedral crystal structure of $\mathrm{MoS}_{2}$ is known to exist, for the purposes of this study, the hexagonal configuration will be assumed.

The selected area electron diffraction patterns from the stoichiometric $\mathrm{MoS}_{2}$ specimen showed definite crystalline spot patterns throughout the sample. The average $\mathrm{MoS}_{2}$ particle appeared to be on the order of hundreds of angstroms in size. The selected area electron diffraction (SAED) pattern of $\mathrm{MoS}_{2}$ in Fig. 4a shows the $\{10 \overline{10}\}$ and $\{1012\}$ reflections with $d$ spacings of 2.73 and $2.50 \AA$, respectively. This high degree of crystallinity could be more or less inferred from the narrow linewidths of the welldefined peaks in the X-ray diffractogram. The high resolution electron microscopy images of these $\mathrm{MoS}_{2}$ crystals shown in Fig. $4 \mathrm{~b}$ illustrate the long range order and nearly defect-free nature of this specimen. The layered structure of this chalcogenide material is also evident along the edge of the crystal. The lattice planes visible in the structure image correspond to the $\{10 \overline{1} 0\}$ and $\{10 \overline{1} 2\}$ reflections in the selected area electron and optical diffraction patterns. Recall that the $\{10 \overline{10}\}$ set of planes which represent the edges of the $\mathrm{MoS}_{2}$ crystal are thought to be the active planes for HDS catalysis. These 

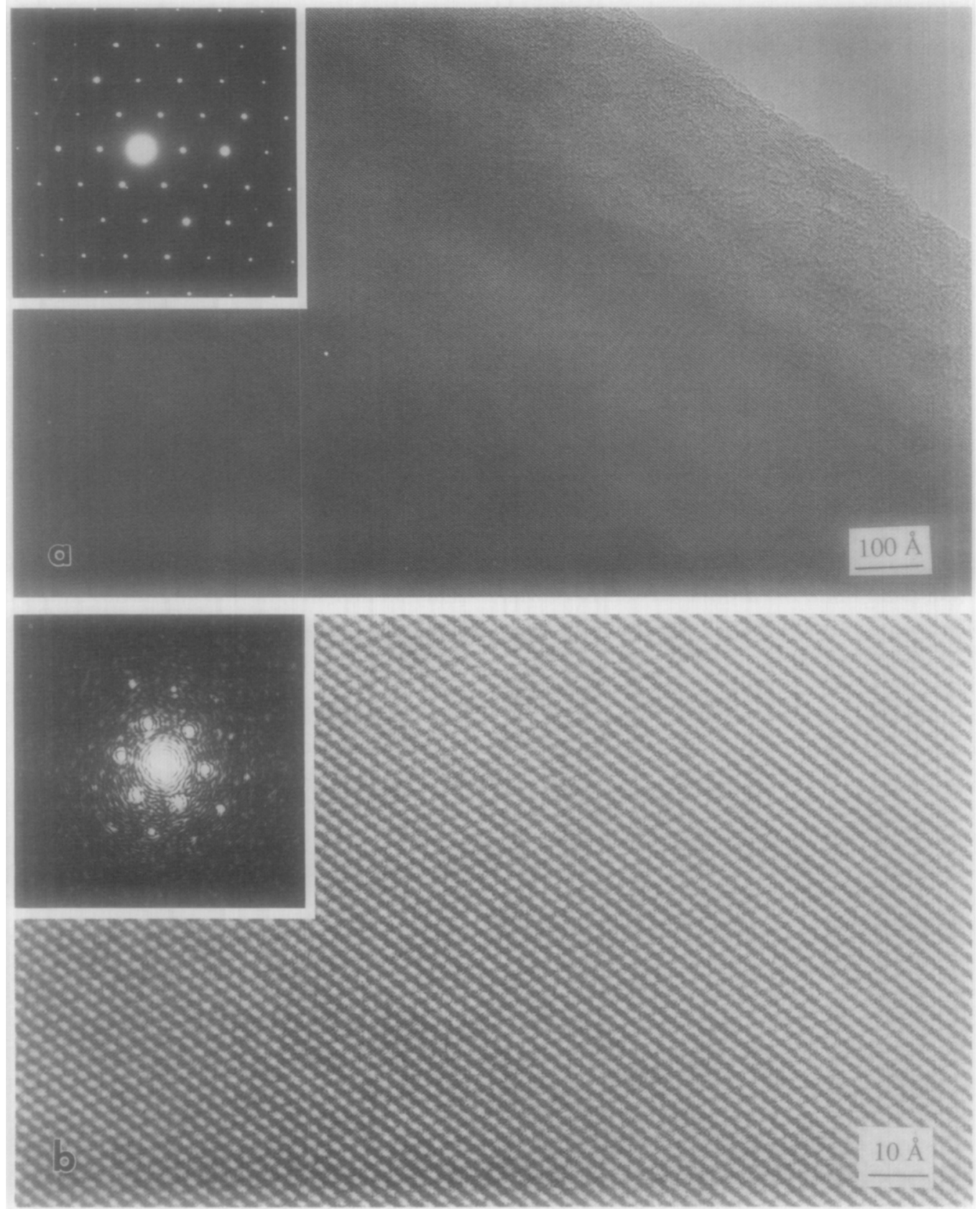

FIG. 4. (a) An HREM image of stoichiometric $\mathrm{MoS}_{2}$ indicating high degrees of crystallinity and long range order. Inset: Selected area diffraction pattern. (b) A higher magnification version of a. Inset: Optical diffraction pattern. The $\{1010\}$ and $\{1012\}$ lattice planes of spacings 2.73 and $2.50 \AA ̊$ respectively are imaged. 
lattice planes, imaged here, are well ordered and defect free. It has been shown by single crystal studies that the $(0001)$ basal planes of $\mathrm{MoS}_{2}$ had low HDS reactivity relative to the edge planes (26).

3.3 Nonstoichiometric $M o S_{1.95}$. With the removal of sulfur atoms and the subsequent creation of anionic vacancies in the molybdenum sulfide lattice a drastic change, relative to the stoichiometric compound, in the structure and morphology takes place. This nonstoichiometric compound is polycrystalline as evidenced by the ring structure observed in the selected area electron diffraction pattern taken from a large particle (Fig. $5 \mathrm{a})$. The reflections from the $(0002),(10 \overline{10})$, and (1014) lattice planes provide the greatest intensity. This lower degree of crystallinity was also detected by X-ray diffraction.

On examining the atomic structure of this compound in HREM, one observes a striking difference in the overall appearance of the molybdenum sulfide. The "slabs" of the basal (0002) lattice planes with $d$ spacings of $6.15 \AA$, which are characteristic of $\mathrm{MoS}_{2}$, are clearly visible as are the atomic structures at various other orientations. The heterogeneity in the $\mathrm{MoS}_{1.95}$ is likely due to the random orientation and stacking of the molybdenum sulfide layers which creates a roughening effect on the catalyst morphology. On closer examination of a region in the image one observes a very disordered structure with a high defect concentration (Fig. 5b). Such defects were found in regions in approximately the same crystallographic orientation as that of the stoichiometric $\mathrm{MoS}_{2}$ images previously shown. The optical diffraction patterns from such regions indicated reflections from the $\{10 \overline{10}\},\{10 \overline{1} 1\}$, and $\{10 \overline{1} 2\}$ lattice planes. The complexities and heterogeneities in this region, however, make it very difficult to decipher whether there is a preferential location of these defects on certain planes. Chianelli and coworkers (27) have identified a "rag-type" $\mathrm{MoS}_{2}$ structure in HDS catalysts. This structure consists of a poorly crystalline $\mathrm{MoS}_{2}$. with highly folded and disordered S-Mo-S layers. In a HREM investigation of graphite-supported $\mathrm{MoS}_{2}$, Sanders (21) observed on optical diffraction patterns the presence of distinct spots corresponding to the $2.13 \AA$ spacings of graphite, but a diffuse arc at $2.74 \AA$ from a disordered layer of $\mathrm{MoS}_{2}$. It was concluded that the $\mathrm{MoS}_{2}$ is not an epitaxed layer but consists of many individual, unaligned particles of $\mathrm{MoS}_{2}$ sheets, lying parallel to the graphite. In an EXAFS study of a sulfided $\mathrm{Mo} / \mathrm{Al}_{2} \mathrm{O}_{3}$ catalyst Vissers et al. have determined by obtaining the Fourier Transform of the $\mathrm{MoK}$ edge that the $\mathrm{MoS}_{2}$ exists in a highly disordered structure with Mo-O and Mo-S bonds (28). In addition, a time differential perturbed angular correlation (TDPAC) analysis has shown that the $\mathrm{MoS}_{2}$ is highly dispersed and defective in a supported HDS catalyst (29).

In the basal planes of a molybdenum sulfide crystal one would not expect surface vacancies since the basal sulfur atoms have completely filled $3 s^{2} 3 p^{6}$ octets due to the three bonds between sulfur and molybdenum. The lack of surface vacancies on these planes would be detrimental to the adsorption of sulfur-containing molecules, thereby hindering the catalytic activity. But, the sulfur atoms on the edge planes are coordinately unsaturated as they are bonded to fewer than three molybdenum cations (23). Therefore, sulfur vacancies do occur on planes such as the $\{10 \overline{10}\}$ and $\{11 \overline{2} 0\}$ edge planes. Furthermore, the sulfur atoms are known to be mobile on the surface of the $\{10 \overline{10} 0\}$ edges (30). The presence of vacancies and the resulting sulfur mobility facilitate a greater number of adsorption modes of thiophene or other sulfur-containing reactants. This explains the higher catalytic activity of edge planes as compared to basal planes.

The deliberate synthesis of a nonstoichiometric, sulfur-deficient molybdenum sulfide 

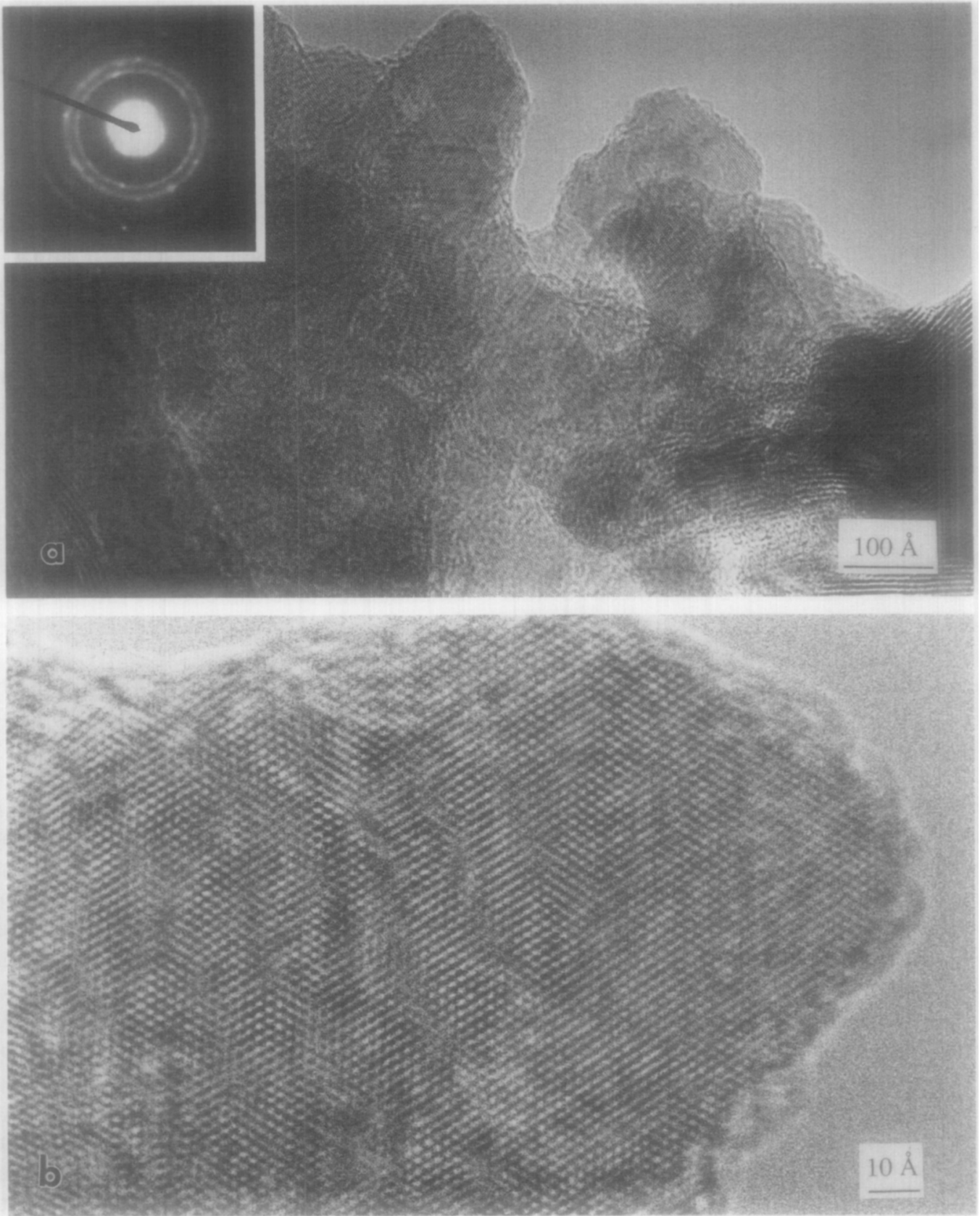

FIG. 5. (a) HREM image of nonstoichiometric $\operatorname{MoS}_{1.95}$ indicating polycrystallinity and structural disorder. The (0002) basal planes of molybdenum disulfide are visible. Inset: The SAED pattern with a ring structure indicating polycrystallinity. (b) A close-up view of a region in a illustrating the high defect concentration of the material. 
compound would lead to an even greater number of anionic vacancies on the edge planes. Consequently, such materials should be highly active for hydrodesulfurization catalysis. This hypothesis was confirmed, as the catalytic activity of the nonstoichiometric $\mathrm{MoS}_{1.95}$ was orders of magnitude higher than that of the stoichiometric $\mathrm{MoS}_{2}$ compound (Table II).

3.4 Promoted samples. The compounds promoted with lower loadings of cobalt showed a slightly higher catalytic activity than the nonstoichiometric $\mathrm{MoS}_{1.95}$ compound but a significantly improved performance as compared to the stoichiometric $\mathrm{MoS}_{2}$ sample. This beneficial trend in thiophene conversion coincides with the presence of a nonstoichiometric $\mathrm{MoS}_{2}$ phase in the cobalt samples as shown in the X-ray diffraction profiles. Two hypotheses can be advanced to explain the formation of the nonstoichiometric molybdenum sulfide phase in the cobalt-promoted samples. First the inclusion of lower charged promoter ions into the $\mathrm{MoS}_{2}$ lattice requires the introduction of sulfur or anionic vacancies to maintain electroneutrality. The replacement of $\mathrm{Mo}^{4+}$ cations by lower-charged Co cations causes the formation of these anionic vacancies. Second, it is possible that the promoter acts as a sulfur scavenger during the catalyst synthesis by forming promoter bulk sulfides and causing the depletion of sulfur atoms needed for the formation of stoichiometric $\mathrm{MoS}_{2}$. As in the unpromoted samples, the selected area electron diffraction patterns of large particles consistently showed ring structures which were indexed to $\mathrm{MoS}_{2}$ (Fig. 6a). This polycrystalline phase when imaged in HREM appeared to be similar to $\mathrm{MoS}_{1.95}$. The distinct (0002) basal planes and the heterogeneity in the random orientation of the $\mathrm{MoS}_{2}$ layers were quite evident in the high resolution images. Once again defect features caused by the sulfur deficiency in the lattice were observed in the region of the edge planes (Fig. 6b).
Elemental EDX maps generated by rastering the electron beam across crystallites of the $\mathrm{Co}_{0.05}$ sample indicated that in some crystallites the cobalt was distributed evenly within the catalyst particle, although the ring structure of the SAED was indexed as sulfur-deficient molybdenum sulfide. But EDX spectra from other regions indicated that some of the cobalt was also segregated toward the edges of the crystallite. In general, there was no definite trend observed regarding the location and distribution of cobalt within the different crystallites. From the EDX data, it cannot be determined with confidence whether the Co is located inside the particles or decorating the surface. Unfortunately, the $\mathrm{K} \mathrm{X}$-ray peak of sulfur occurs at the same energy as one of the Mo $L \alpha$ peaks. This peak overlap prevents the unambiguous determination of the presence of sulfur in regions containing Mo. Therefore, one cannot say with certainty whether or not Co is associated with sulfur or merely present in elemental form within the molybdenum sulfide structure.

In prior Auger mapping and TEM studies on single crystals and unsupported HDS catalysts, respectively, the authors drew the conclusion that the cobalt was situated on the edges of the $\mathrm{MoS}_{2}(31-33)$. However, the TEM study was performed with an instrument not capable of fully resolving the $2.73 \AA$ edge planes. By correlating our elemental distribution obtained by AEM with the structural information obtained by HRTEM we can infer that in some cases the presence of cobalt is related to the formation of the highly disordered nonstoichiometric molybdenum sulfide phase.

The cobalt-promoted samples with Co loadings up to $\mathrm{Co}_{0.3}$ had similar composition, structure, and morphology as $\mathrm{Co}_{0.05}$ along with improved catalytic behavior. However, when the cobalt loading was increased to $\mathrm{Co}_{0.5}$ and $\mathrm{Co}_{0.6}$, the structure, crystallinity, and morphology transformed dramatically coinciding with the decrease in 

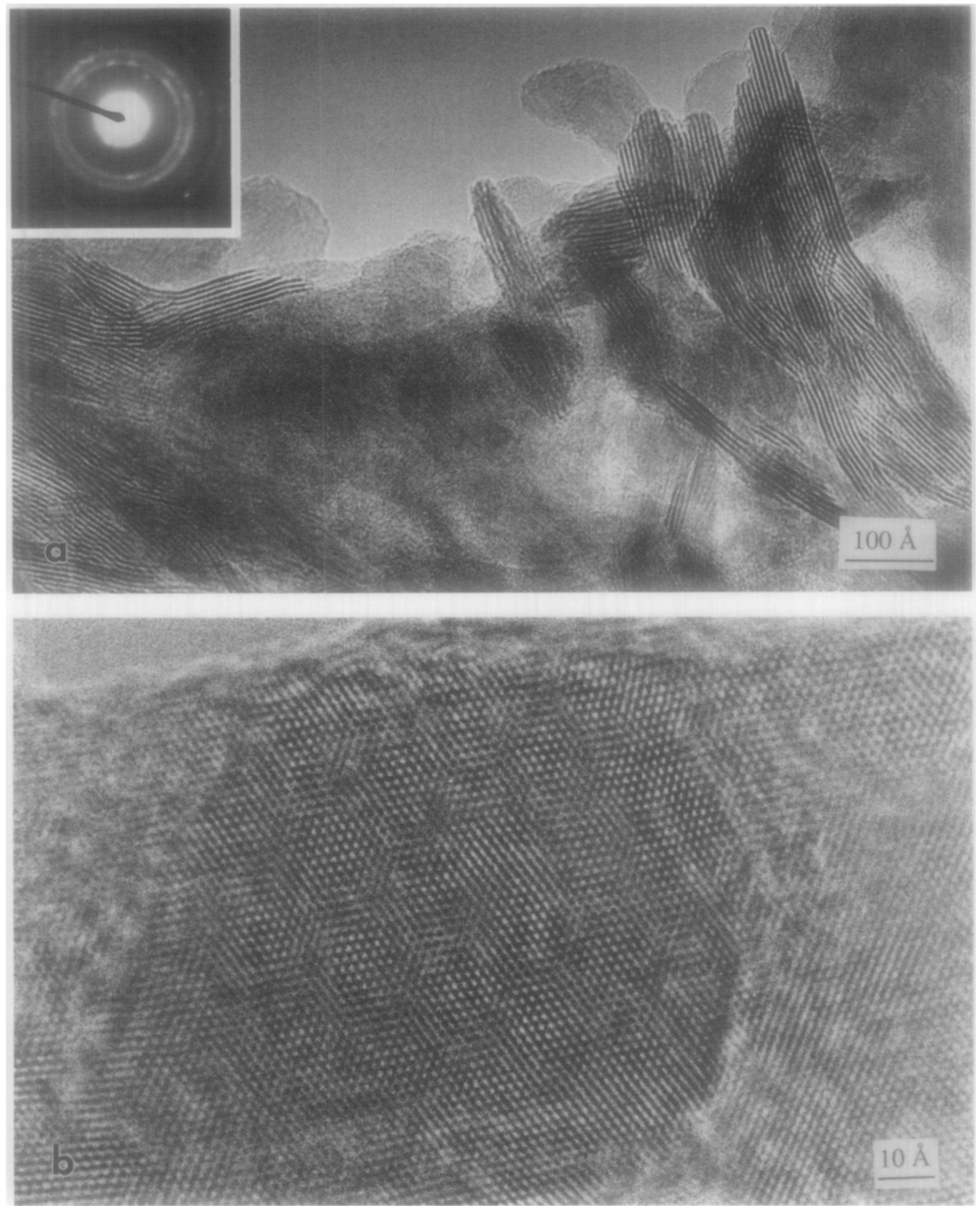

FIG. 6. (a) A high resolution electron micrograph from $\mathrm{Co}_{0.05} \mathrm{Mo}_{0.975} \mathrm{~S}_{2}$ showing features similar to the nonstoichiometric $\mathrm{MoS}_{1.95}$ with structural disorder and polycrystallinity. The $6.15 \AA$ lattice fringes of the basal plane of molybdenum disulfide can be observed. Inset: SAED pattern which can be indexed to $\mathrm{MoS}_{2}$. (b) A high magnification version of a region in a indicating a higher defect concentration than the stoichiometric $\mathrm{MoS}_{2}$. 

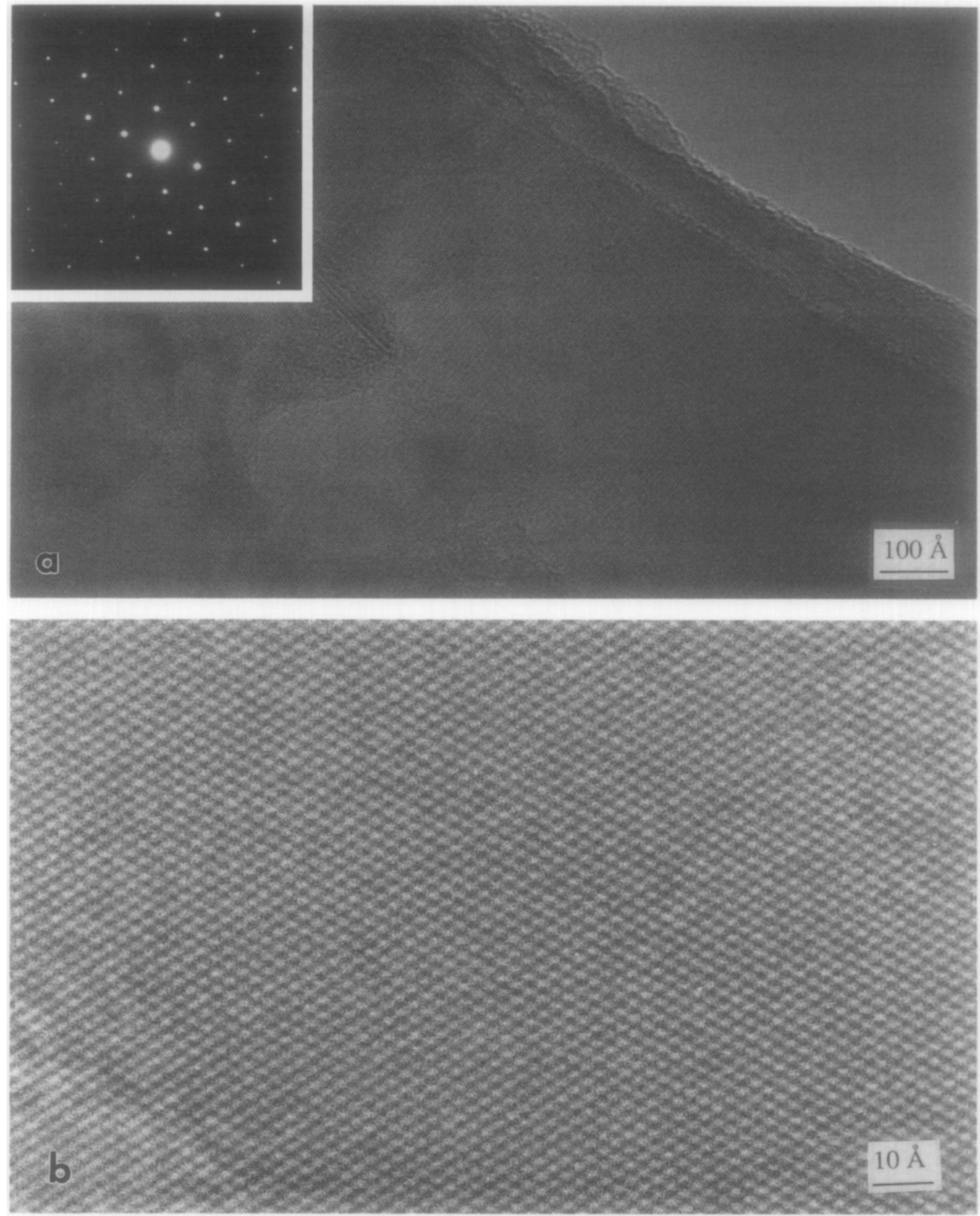

FIG. 7. (a) HREM image from $\mathrm{Co}_{0.5} \mathrm{Mo}_{0.75} \mathrm{~S}_{2}$ showing the $\mathrm{MoS}_{2}$ phase as well crystallized and ordered. Inset: Selected area diffraction pattern of $\mathrm{MoS}_{2}$. (b) A close-up view of region in a indicating a structure similar to the stoichiometric $\mathrm{MoS}_{2}$ which is relatively defect free. 

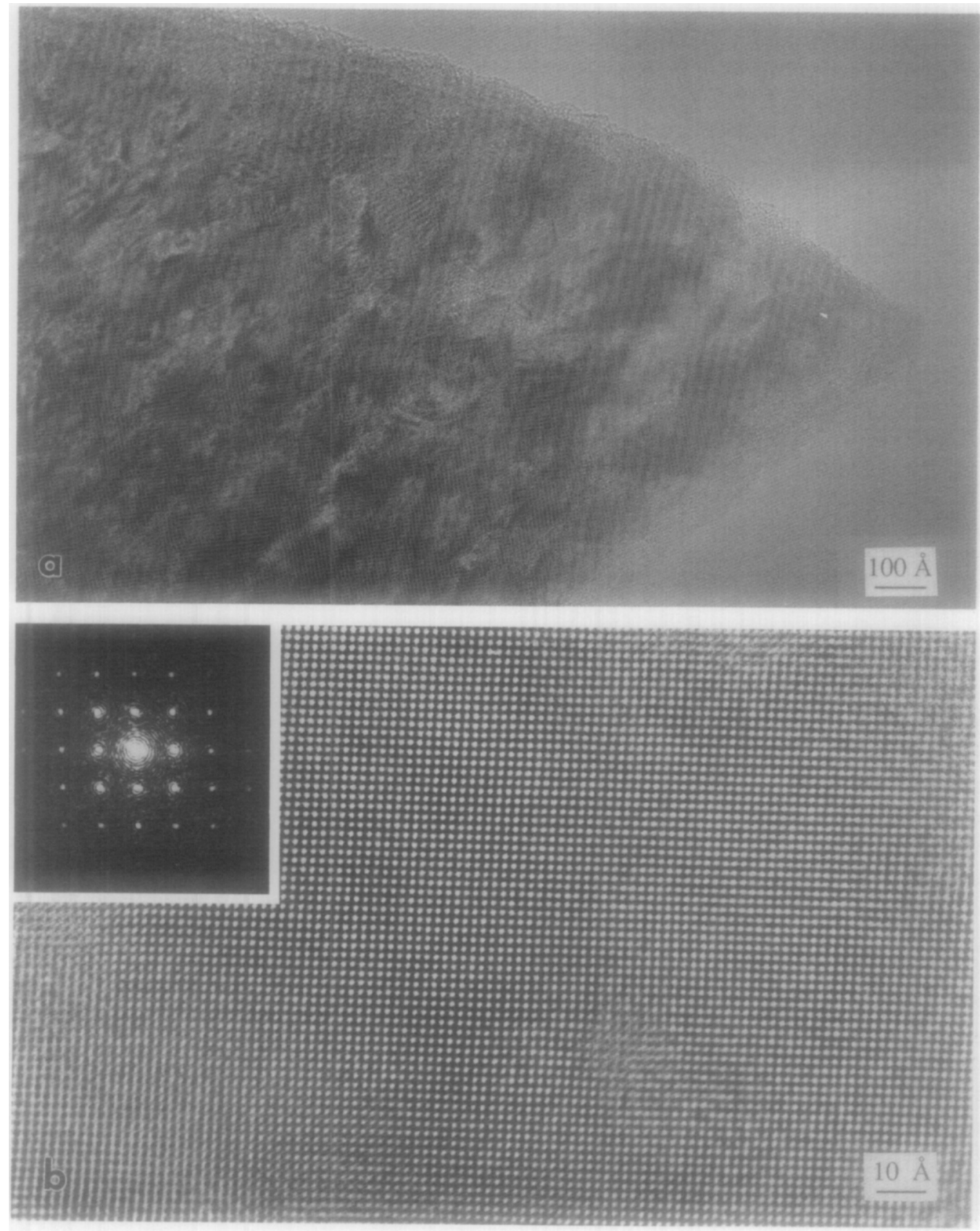

FIG. 8. (a) HREM image from a region from $\mathrm{Co}_{0.5} \mathrm{Mo}_{0.75} \mathrm{~S}_{2}$ identified to be most likely $\mathrm{Co}_{4} \mathrm{~S}_{3}$. (b) $\mathrm{A}$ close-up view of small area in a. Inset: Optical diffraction pattern of this region shows a cubic structure with a [110] orientation. 

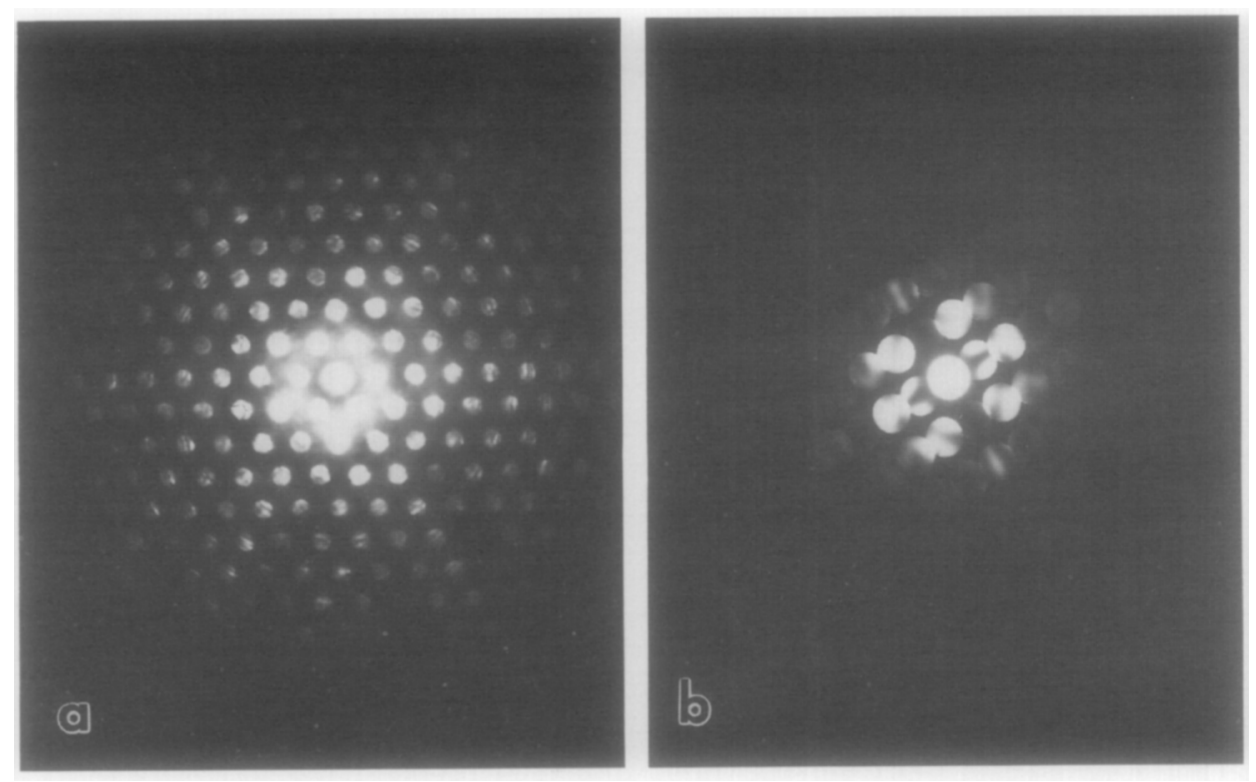

FIG. 9. Microdiffraction patterns from $\mathrm{Co}_{0.5} \mathrm{Mo}_{0.75} \mathrm{~S}_{2}$ of (a) unreacted molybdenum with a [111] orientation and (b) [011] zone axis of $\mathrm{CoS}_{2}$.

the thiophene conversion rate. The X-ray diffraction profiles indicated the absence of the nonstoichiometric molybdenum sulfide and the formation of a crystalline stoichiometric $\mathrm{MoS}_{2}$ phase. This difference was also represented in the SAED patterns where now well-defined spot patterns were observed similar to the ones seen in the stoichiometric $\mathrm{MoS}_{2}$ diffraction patterns (Fig. $7 a)$. The high resolution images also reverted to the well-ordered, crystalline structure of $\mathrm{MoS}_{2}$. The layers of this compound are no longer in random orientations but stacked in order. Figure $7 \mathrm{~b}$ shows the $\{10 \overline{10}\}$ set of lattice planes which constitute the edges of the crystal. Like the stoichiometric $\mathrm{MoS}_{2}$ case, these regions appear to be defect free.

It was also possible to locate and image some of the lesser sulfide phases in the high cobalt loading materials. Figure 8 shows a region identified as $\mathrm{Co}_{4} \mathrm{~S}_{3}$ in the $\mathrm{Co}_{0.5}$ sample. This region was present as a separate particle. The presence of the other phases as well as metallic molybdenum was also detected by using microdiffraction techniques. Representative convergent beam electron diffraction patterns of $\mathrm{CoS}_{2}$ and Mo are displayed in Fig. 9. In almost all cases these other sulfide phases appeared to exist as separate crystallites apart from the molybdenum sulfide particles.

In addition, analytical electron microscopy of a high cobalt-loaded sample, such as $\mathrm{Co}_{0.6}$, indicated that, by and large, cobalt was not located within the well-ordered, crystalline structures of $\mathrm{MoS}_{2}$. The bulk of the cobalt, instead, was found by microdiffraction to be in the form of separate particles of cobalt sulfides confirming our previous results by HRTEM. But, within a few of these relatively well-crystallized particles, where there appeared to be regions with some structural disorder, cobalt atoms were detected. This result reaffirms the argument that the structural disorder and the formation of the nonstoichiometric molybdenum sulfide phase is related to the presence of 

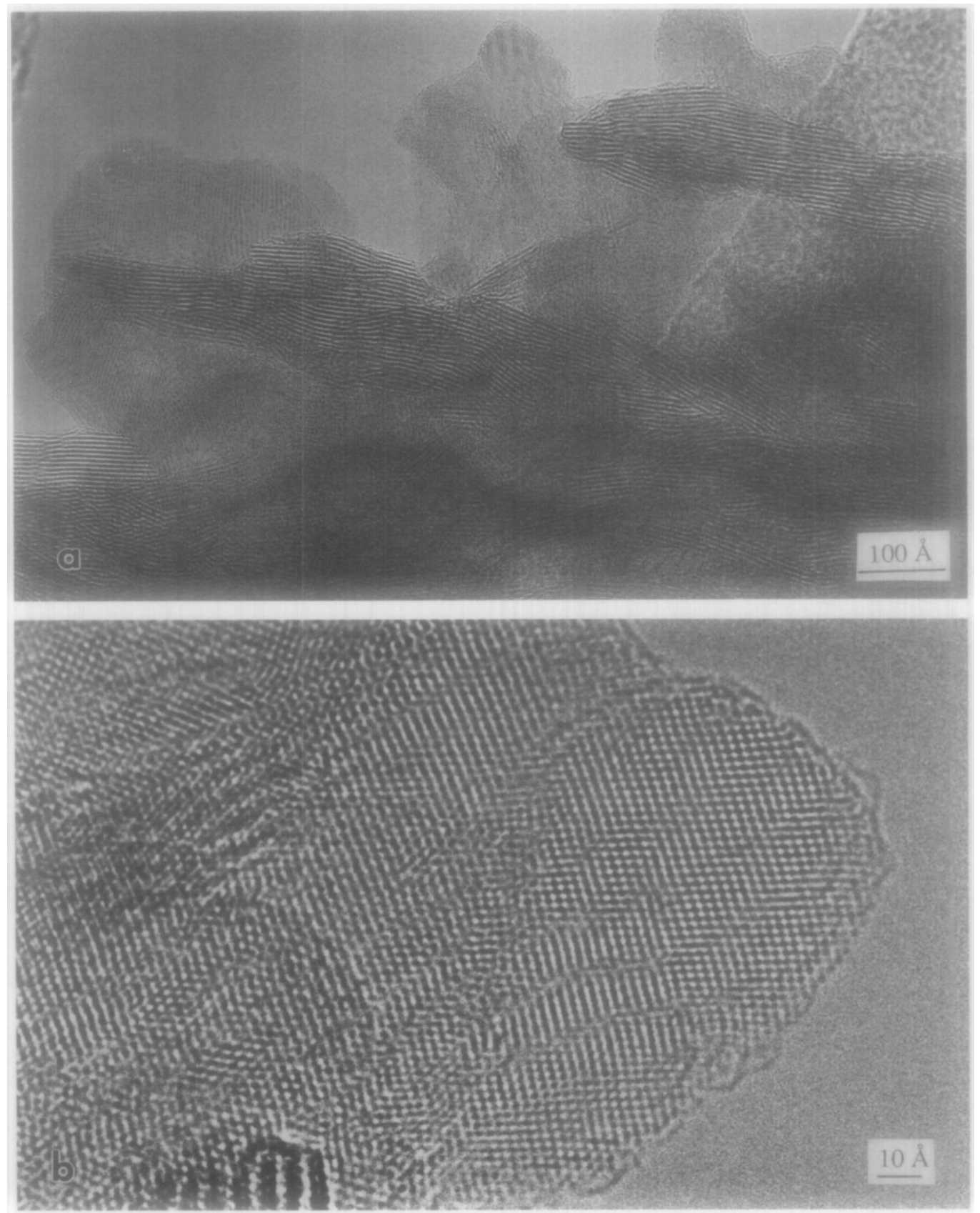

FIG. 10. (a) High resolution electron micrograph from $\mathrm{Fe}_{0.1} \mathrm{Mo}_{0.93} \mathrm{~S}_{2}$ showing a $\mathrm{MoS}_{2}$ region similar to the nonstoichiometric case. (b) A close-up view of top region showing the presence of defects at an atomic level. 
cobalt. It is interesting to draw a comparison between the scenario decribed here and the previously postulated model of cobalt " $\mathrm{dec}$ orating" the edges of the $\mathrm{MoS}_{2}(11)$.

The iron-promoted solid state samples had microstructures similar to that of the cobalt series with lower promoter loadings. The X-ray diffractograms showed the prescnce of the nonstoichiometric molybdenum sulfide phase in the entire iron series. Again, the HREM images indicated, as in the cobalt-promoted series, a highly disordered and defective molybdenum sulfide structure (Figs. 10a and 10b). In addition, separate particles of pyritic $\mathrm{FeS}_{2}$ could be identified by microdiffraction techniques.

Previous studies have reported that the iron promoter does not have a beneficial effect on the HDS activity $(4,34,35)$. Theoretical investigations $(4,36)$ on $\mathrm{Fe}-\mathrm{Mo}$ systems have predicted that due to the lack of electron transfer capabilities caused by the electronic configuration of iron, improved catalytic trends would not be observed. Therefore, the enhanced HDS activity in our iron-promoted solid state catalysts can be attributed mainly to structural transformations of the molybdenum sulfide lattice.

\section{Conclusions}

It appears that the activity increase displayed by these model solid state catalysts is associated with a structural change in the $\mathrm{MoS}_{2}$ crystal lattice. This change may be induced by either the addition of a promoter, such as $\mathrm{Co}$ or $\mathrm{Fe}$, or by the removal of sulfur directly from the synthesis charge. Both Group VIII promotion and an intentional sulfur deficiency result in structural changes which were followed by XRD and AFM. Furthermore, it was possible to monitor the promoter and sulfur deficiency effects on the (0002) basal plane as well as the $(10 \overline{10}),(10 \overline{1} 1)$, and (10 $\overline{1} 2)$ planes directly using HREM. The results of these studies indicate that both active and less active cata- lysts all have similar structure along the (0002) plane, but the other planes, specifically the (1010), (1011), and (1012) planes, all show a high concentration of defects and disorder in the catalytically active samples. These highly defective planes, which have been correlated with an increased HDS activity, may be interpreted as the much cited "cdge" planes bclieved to be responsible for the HDS activity of industrial catalysts. In the low activity catalysts these same planes are well ordered and defect free.

\section{Acknowledgments}

The authors thank Mr. Vivion Shull of the Department of Physics and Astronomy, Michigan State University for the use of and his assistance with the VGSTEM analytical electron microscope. One of us (M.A.V.G.) thanks the MEC/Fulbright Committee for financial support.

\section{References}

1. H. KNÖzINGER, in "Proceedings, 9th International Congress on Catalysis, Calgary, 1988' (M. J. Phillips and M. Ternan Eds.), Vol. 5, p. 20, The Chemical Institute of Canada, Ottawa, (1988).

2. R. Prins, V. H. J. DE BeER, ANd G. A. Somorjai, Catal. Rev. Sci. Eng. 31, 1 (1989).

3. J. M. J. G. Lipsch and G. C. A. Schuit, J. Catal. 15, 179 (1969).

4. B.C. Gates, J. R. Katzer, and G. C. A. Schuit, in "Chemistry of Catalytic Processes," Chap. 5, McGraw-Hill, New York (1979).

5. F. E. Massoth, J. Catal. 36, 154 (1975).

6. R. J. H. Voorhoeve and J. C. M. Stuiver, $J$. Catal. 23, 243 (1971).

7. A. L. Farragher and P. Cossee, in "Proceedings, 5th Internat. Congress on Catalysis, Palm Beach, 1972" (J. W. Hightower, Ed.), p. 1301, North-Holland, Amsterdam (1973).

8. G. Hagenbach, P. Courty, and B. Delmon, $J$. Catal. 23, 295 (1971).

9. B. Delmon, Amer. Chem. Soc. Div. Pet. Chem. Prepr., 22, 503 (1977).

10. G. Hagendach, P. Courty, and B. Delmon, $J$. Catal. 31, 264 (1973).

11. H. Topsøe, B. S. Clausen, R. Candia, C. Wivel, and S. Mørup, J. Catal. 68, 433 (1981).

12. C.Wivel, R. Candia, B. S. Clausen, S. Mørup, AND H. Tops $\emptyset \mathrm{E}, J$. Catal. 68, 453 (1981).

13. H. Tors $\phi \mathrm{E}$, B. S. Clausen, and S. Mørup, $I y-$ perfine Interact. 27, 231 (1986). 
14. R. Prins, S. M. A. M. Bouwens, D. C. KonINGSBERGER, AND V. H. J. DE BEER, "EXAFS and XPS of Sulfided $\mathrm{Co}(\mathrm{Ni})-\mathrm{Mo} / \mathrm{C}$ and $\mathrm{Co}(\mathrm{Ni})-\mathrm{Mo} /$ $\mathrm{Al}_{2} \mathrm{O}_{3}$ Catalysts," 11 th North American Meeting of the Catalysis Society, Dearborn, MI, May 7-11 (1989).

15. R. Candia, B. S. Clausen, and H. Tops $\phi$ E, Bull. Soc. Chim. Belg. 90, 1225 (1981).

16. S. GöBölös, Q. Wu, ANd B. Delmon, Appl. Catal. 13, 89 (1984).

17. M. A. Villa Garcia, J. H. Lindner, A. SachDEV, AND J. SCHWANK, J. Catal. 119, 388 (1989).

18. M. A. Villa Garcia, J. H. Lindner, A. SaChDev, ANd J. Schwank, Appl. Catal., 56, 281 (1989).

19. S. Ergun, Phys. Rev B 1, 3371 (1970).

20. H. Tops $\varnothing$ E, B. S. Clausen, R. Candia, C. Wivel, AND S. MфRUP, Bull. Soc. Chim. Belg. 90, 1189 (1981).

21. J. V. SANDERS, J. Electron Microsc. Tech. 3, 67 (1986).

22. F. Delannay, Appl. Catal. 16, 135 (1985).

23. T. F. Hayden and J. A. Dumesic, J. Catal. 103, 366 (1987).

24. P. Ratnasamy and S. Sivasankar, Catal. Rev. Sci. Eng. 22, 401 (1980).

25. G. A. Tsigdinos, in "Topics in Current Chemistry" (M. J. S. Dewar et al., Fds.), Vol. 76, p. 65, Springer-Verlag, Berlin/New York (1978).
26. M. H. Farias, A. J. Gellman, G. A. Somorjai, R. R. Chianelli, and K. S. Liang, Surf. Sci. 140, 181 (1984).

27. R. R. Chitanelli, E. B. Prestridge, T. A. PecorARo, AND J. P. De Neufville, Science 203, 1105 (1979); R. R. Chianelli, Int. Rev. Phys. Chem. 2, 127 (1982).

28. J. P. R. Vissers, B. SChefFer, V. H. J. DE BeER, J. A. Moulijn, AND R. Prins, J. Catal. 105, 277 (1987).

29. Vogdt, C., Butz, T., LeRf, A., AND KNöZINGER, H., Polyhedron 5, 95 (1986).

30. A. L. Farragher, Adv. Colloid Interface Sci. 11, 3 (1979).

31. O. Sørenson, B. S. Clausen, R. Candia, and H. TOPS 6 E, Appl. Catal. 13, 363 (1985).

32. R. R. Chianelli, A. F. Ruppert, S. K. Behal, B. H. KeAR, A. Wold, AND R. KershaW, J. Catal. 92, 56 (1985).

33. S. K. Behal, R. R. Chianelli, and B. H. Kear, Mater. Lett. 3, 381 (1985).

34. D. S. Thakur, P. Grange, and B. Delmon, $J$. Less-Common Met. 64, 201 (1979).

35. S. Göbölös, Q. Wu, A. Loivier, F. Delannay, and B. Delmon, J. Chem. Soc., Faraday Trans. I 82, 2423 (1983).

36. S. Harris and R. Chianelli, J. Catal. 98, 17 (1986). 